\title{
Association Between BMI and Risk of OSA in COPD Patients: a Multicenter Cross-sectional Study in China
}

\section{Mengqing Xiong}

Wuhan University Renmin Hospital

\section{Zhiling Zhao}

Beijing Chaoyang Hospital

Qingrong Nie

Liangxiang Hospital of Yanjing Medical College, Capital Medical University

\section{Zhihong Shi}

Xi'an Jiaotong University Medical College First Affiliated Hospital

\section{Bin Wu}

Affiliated Hospital of Guangdong Medical University

\section{Haizhen Yang}

Renmin Hospital of Wuhan University

\section{Fang Yue}

Renmin Hospital of Wuhan University

\section{Yan Song}

Renmin Hospital of Wuhan university

Xin He

Renmin Hospital of Wuhan University

\section{Mengmei Wang}

Renmin Hospital of Wuhan University

Ke Hu ( $\sim$ huke-rmhospital@163.com )

Renmin Hospital of Wuhan University https://orcid.org/0000-0001-9862-7239

\section{Research}

Keywords: BMI, OSA, COPD, risk, model

Posted Date: May 10th, 2021

DOl: https://doi.org/10.21203/rs.3.rs-484633/v1 
License: (c) (i) This work is licensed under a Creative Commons Attribution 4.0 International License. Read Full License 


\section{Abstract}

Background: BMI increase risk for obstructive sleep apnea (OSA), while low BMI and overweight/obesity has paradoxical effect on chronic obstructive pulmonary disease (COPD) outcomes. We aimed to examine the association between BMI and OSA risk in COPD patients.

Methods: A number of 1637 COPD subjects included in the final analysis. Logistic regression was performed to investigate the association between BMI or BMI category and OSA risk. Using restricted cubic splines to flexibly model a nonlinear relationship.

Results: In this COPD cohort, BMI or BMI category was significantly associated with risk of OSA. Using BMI $18.5-23.9 \mathrm{~kg} / \mathrm{m}^{2}$ (normal weight) as a reference group, the overweight group (BMl: $24-27.9 \mathrm{~kg} / \mathrm{m}^{2}$ ) (OR 1.348, 95\% $\mathrm{Cl} 1.057-1.718)$ and the obese group $\left(\mathrm{BMI} \geq 28 \mathrm{~kg} / \mathrm{m}^{2}\right)(\mathrm{OR} 2.596,95 \% \mathrm{Cl} 1.825-3.692)$ had higher risk of OSA in the crude model; after the sex- and age-adjusted, the association remained significant, while in the fully adjusted model, the obese group still had 2.623 times higher risk and the overweight group had a trend of higher risk but the underweight group $\left(B M \mathrm{~K}<18.5 \mathrm{~kg} / \mathrm{m}^{2}\right)$ also showed a trend of higher OSA risk than the normal weight group ( $p$ value 0.071 ).

In restricted cubic spline model, BMI exhibited a J-shaped association with OSA, and the risk of OSA reached a nadir at BMls in the range of $20-24 \mathrm{~kg} / \mathrm{m}^{2}$, with a positive association above or below.

Conclusions: BMI had a J-shaped association with OSA in this COPD patient cohort; lower or higher BMls were associated with an increased risk of OSA.

Trial registration: This study registered in ClinicalTrials.gov (Clinical Trials ID: NCT 03182309).

\section{Background}

Chronic obstructive pulmonary disease (COPD) and obstructive sleep apnea (OSA) are both highly prevalent, and the concurrence of these diseases is called overlap syndrome (OVS). ${ }^{1}$ COPD is a public health issue due to the related morbidity, disability and mortality; COPD affects $13.7 \%$ of Chinese people aged 40 years or older and is the third leading cause of death. ${ }^{2,3}$ OSA, characterized by repetitive upper airway collapse during sleep, is related to many adverse health conditions that decrease quality of life and survival. ${ }^{4-6}$ OSA is a major comorbidity of COPD that increases the rates of COPD exacerbation, hospital readmission and mortality. $2,7-10$

Obesity assessed by BMI is associated with an increased risk for many chronic diseases as well as mortality. ${ }^{11,12}$ Studies show that BMI is inversely associated with the prognosis of COPD; low body mass index (BMI) is associated with worse outcomes, and overweight/obesity has a protective effect. ${ }^{13,14} \mathrm{An}$ increased BMI is a well-known risk factor for OSA. ${ }^{6,15}$ However, studies about BMI in OVS patients are blurred, and it is unclear whether the risk of OSA starts to increase with overweight or just with obesity and whether underweight influences risk. 
We aimed to examine in detail the association between BMI and the risk of OSA in COPD patients.

\section{Methods}

\section{Study design and ethics}

This was a prospective, observational, multicenter study of COPD patients supported by the National Key Research and Development Program of China (project number: 2016YFC1304403) and registered in ClinicalTrials.gov (Clinical Trials ID: NCT 03182309). The protocol of this study was reviewed and approved by the Ethics Committee of Renmin Hospital of Wuhan University (No. 2017K-C014). The trial was conducted in compliance with the Declaration of Helsinki.

\section{Participants and flow}

This was a national multicenter study. From Dec 2016 to Jan 2020, patients with COPD who met the inclusion and exclusion criteria were enrolled as study candidates from five Chinese tertiary hospitals. The inclusion criteria were as follows: subjects aged at least 40 years old with a diagnosis of COPD conforming to the GOLD guidelines. Candidates were excluded based on the following: 1) those who were less than 40 years old or pregnant; 2) patients with evidence of bronchial asthma, bronchiectasis, pulmonary fibrosis, intratracheal neoplasms, destructive sequelae of tuberculosis, etc.; 3) patients with other diseases affecting survival, such as neoplastic diseases, renal insufficiency, or acute myocardial infarction; 4) those with a history of stroke, heart failure, neuromuscular disease, cognitive impairment or other mental or psychological diseases that would prevent completion of pulmonary function tests questionnaires or polysomnography (PSG); and 5) those who had other sleep disorders, such as obesity hypoventilation syndrome.

Participants were recruited from four Chinese tertiary hospitals. Every subject enrolled in this study was informed about the purpose and process of the study, and written consent forms were signed. Baseline information and demographics were obtained from patients' and their electronic medical records. The questionnaire survey was administered after subjects were enrolled and while lung function tests or PSG were performed while patients were relatively stable.

Data were exported from the electronic database of this program. The study flow diagram is shown in Figure 1. Subjects who dropped out before their data were input into the electronic system of this project were excluded from this prospective study. Some subjects were excluded for the following reasons: 128 patients were unable to complete lung function tests for a severe condition or refused, 161 could not tolerate or refused to perform PSG (77 patients did not complete lung function tests), and 62 had unqualified PSG data. Finally, a total of 1637 stable subjects were included in this analysis.

\section{Lung Function Test}

Lung function tests were performed under the guidance of professional technicians by using a spirometer (MasterScreenBody, Jaeger, Germany). The diagnosis and severity of COPD were assessed according to 
Global Initiative for Chronic Obstructive Lung Disease (GOLD) guidelines. ${ }^{2}$ Those with a ratio of forced expiratory volume in 1 second (FEV1)/forced vital capacity (FVC) in a post-bronchodilator less than $70 \%$ were diagnosed with COPD, and airflow limitation was classified based on the value of FEV1 in the postbronchodilator.

\section{PSG and OSA Diagnostic Criteria}

All subjects with confirmed COPD underwent assessment of sleep events with a multichannel sleep diagnostic system (SOMNOscreen Plus Tele PSG, SOMNOmedic GmbH, Germany) in the sleep laboratory overnight monitoring. All tracings were manually scored according to the American Academy of Sleep Medicine criteria. ${ }^{16}$ Those who experienced apnea-hypopnea index $(\mathrm{AHI}) \geq 5$ events/h during sleep were considered to have OSA.

\section{Statistical Analyses}

A total of 1637 COPD subjects were included in the final analysis. Patients were divided into OVS and COPD-only groups. BMI was classified into four categories according to Chinese criteria: ${ }^{17}$ underweight $\left(B M l<18.5 \mathrm{~kg} / \mathrm{m}^{2}\right.$ ), normal weight (BMl $18.5-23.9 \mathrm{~kg} / \mathrm{m}^{2}$ ), overweight (BMl $24-27.9 \mathrm{~kg} / \mathrm{m}^{2}$ ) and obese $\left(\mathrm{BMI} \geq 28 \mathrm{~kg} / \mathrm{m}^{2}\right)$. Data are presented as the mean \pm standard deviation (SD) for continuous variables and frequency or percentages for categorical variables. Baseline characteristics and demographics were compared between the two groups. Independent t-tests were used for normally distributed continuous variables, the Mann-Whitney U-test was used for nonnormally distributed continuous variables, and the $\chi^{2}$ test was used for categorical variables. Logistic regression was conducted to examine the associations between BMI or BMI category and risk of OSA in detail. Collinearity between independent variables was also assessed. In logistic regression analysis, the normal weight (BMI 18.5-23.9 $\mathrm{kg} / \mathrm{m}^{2}$ ) group was taken as the reference category. The crude model had no adjustment. Model 1 was adjusted for sex and age. Model 2 was a fully adjusted model that adjusted for sex, age, job, education level, income, smoking status, alcohol consumption, FEV1\%pred, acute exacerbation in previous year, and hypertension. To further investigate the relationship between BMI and OSA, restricted cubic spline in a fully adjusted model with five knots was performed to flexibly model and visualize the relation of BMI with OSA. A p value (two tailed) of less than 0.05 was considered statistically significant. Analyses were performed using SPSS 24.0 (IBM, Armonk NY, USA) and R (version 4.0.2 basic).

\section{Results}

\section{Baseline and Demographic Characteristics}

Finally, 1637 patients who completed pulmonary function tests and PSG were involved in the study. According to the American Academy of Sleep Medicine (AASM) guidelines, 1076 (65.7\%) subjects with $\mathrm{AHI} \geq 5$ events/h were divided into the OVS group, and the others were divided into the COPD-only group. In this group of COPD patients, male patients accounted for over $80 \%$ of the sample, and the proportion 
was even higher in the OVS group ( $85.5 \%$ vs $81.6 \%, p=0.042)$. The average age of this population was more than 65 years old, and retirees accounted for more than $45 \%$ of the sample. Regarding occupation, office clerks and workers were more common in the OVS group (11.5\% vs $6.1 \%$ ) (11.6 vs 8.9$)$ ), while farmers were more common in the COPD-only group (31.0\% vs $22.6 \%$ ). The OVS group had higher rates of college or higher education and middle income, and the COPD-only group had higher rates of primary school or below education and general income. Current smoking ( $56.3 \%$ vs $48.0 \%)$ and alcohol consumption ( $35.5 \%$ vs $8.6 \%$ ) were more prevalent in the OVS cohort, and more COPD-only patients quit smoking (32.4\% vs $24.5 \%$ ) or drinking alcohol ( $27.5 \%$ vs $7.9 \%)$. Regarding BMI, the OVS group had a higher proportion of overweight $(29.4 \%$ vs $27.3 \%)$ or obese $(17.4 \%$ vs $8.4 \%)$ individuals, and COPD-only patients had a higher proportion of normal weight individuals (51.9\% vs $41.4 \%$ ). Spirometry tests showed that the OVS group had better lung function with a higher proportion of GOLD1 or COLD2 subjects, while the COPD-only group had more severe cases. Apparently, the OVS group had more characteristics indicating severe sleep-disordered breathing, such as higher $\mathrm{AHI}$, longer $\mathrm{TS} 90 \%$, and lower nadir $\mathrm{SaO}_{2}$ and average $\mathrm{SaO}_{2}$, during the full-night PSG. There were no significant differences in age, Modified Medical Research Council (mMRC) dyspnea scale score, COPD Assessment Test (CAT) score or duration of COPD, but concurrent OSA was associated with increased occurrence of acute exacerbation on the basis of clinical data and patient self-reports. A higher prevalence of hypertension could be found in OVS patients, but no difference was found in coronary heart disease, diabetes mellitus or cerebrovascular disease (Table 1). 
Table 1

Baseline Characteristics and Demographics of the patients

\begin{tabular}{|c|c|c|c|c|}
\hline Parameter & $\begin{array}{l}\text { Total }(n= \\
1637)\end{array}$ & $\begin{array}{l}\text { COPD only }(n= \\
561)\end{array}$ & $\begin{array}{l}\text { OVS( } n= \\
1076)\end{array}$ & $\begin{array}{l}\mathrm{P} \\
\text { Value }\end{array}$ \\
\hline Sex, male, n(\%) & 1378(84.2) & $458(81.6)$ & $920(85.5)$ & 0.042 \\
\hline Age, yr & $65.9 \pm 9.2$ & $65.7 \pm 8.7$ & $66.0 \pm 9.5$ & 0.537 \\
\hline Job, n(\%) & & & & $<0.001$ \\
\hline Unemployment & 132(8.1) & $49(8.7)$ & $83(7.7)$ & \\
\hline Retirement & $755(46.1)$ & $254(45.3)$ & $501(46.6)$ & \\
\hline Office clerk & $158(9.7)$ & $34(6.1)$ & $124(11.5)$ & \\
\hline Worker & $175(10.7)$ & $50(8.9)$ & $125(11.6)$ & \\
\hline Farmer & $417(25.5)$ & $174(31.0)$ & $243(22.6)$ & \\
\hline Education level, n(\%) & & & & 0.003 \\
\hline Primary school and less & $519(31.7)$ & 197(35.1) & $322(29.9)$ & \\
\hline Middle and high school & $892(54.5)$ & $307(54.7)$ & $585(54.4)$ & \\
\hline College and higher & $226(13.8)$ & $57(10.2)$ & $169(15.7)$ & \\
\hline Income, n(\%) & & & & 0.019 \\
\hline High income & $21(1.3)$ & $6(1.1)$ & $15(1.4)$ & \\
\hline Middle income & $156(9.5)$ & $38(6.8)$ & 118(11.0) & \\
\hline General income & $1460(89.2)$ & $517(92.2)$ & $943(87.6)$ & \\
\hline Smoking states & & & & 0.001 \\
\hline Never & $316(19.3)$ & $110(19.6)$ & 206(19.1) & \\
\hline Former & $446(27.2)$ & $182(32.4)$ & $264(24.5)$ & \\
\hline Current & $875(53.5)$ & $269(48.0)$ & $606(56.3)$ & \\
\hline Alcohol consumption, n(\%) & & & & 0.004 \\
\hline Never & $968(59.1)$ & $359(64.0)$ & $609(56.6)$ & \\
\hline Former & 133(8.1) & $154(27.5)$ & $85(7.9)$ & \\
\hline
\end{tabular}

Continuous variables were described as means \pm SD. Categorical variables were expressed as percentages. $P$ value for the difference between the groups. COPD, chronic obstructive pulmonary disease. OVS, overlap syndrome. BMI, body mass index. GOLD, the global initiative for chronic obstructive lung disease. mMRC dyspnea scale score, modified medical research council dyspnea scale score. CAT score, COPD assessment test score. 


\begin{tabular}{|c|c|c|c|c|}
\hline Parameter & $\begin{array}{l}\text { Total }(n= \\
\text { 1637) }\end{array}$ & $\begin{array}{l}\text { COPD only }(n= \\
561)\end{array}$ & $\begin{array}{l}\text { OVS }(n= \\
1076)\end{array}$ & $\begin{array}{l}\mathrm{P} \\
\text { Value }\end{array}$ \\
\hline Current & $536(32.7)$ & $48(8.6)$ & $382(35.5)$ & \\
\hline $\mathrm{BMI}\left(\mathrm{kg} / \mathrm{m}^{2}\right)$ & $23.53 \pm 4.33$ & $22.90 \pm 4.01$ & $23.87 \pm 4.46$ & $<0.001$ \\
\hline $\mathrm{BMI}\left(\mathrm{kg} / \mathrm{m}^{2}\right)$ & & & & $<0.001$ \\
\hline underweight $\left(\mathrm{BMI}<18.5 \mathrm{~kg} / \mathrm{m}^{2}\right), \mathrm{n}(\%)$ & 197(12.0) & $70(12.5)$ & $127(11.8)$ & \\
\hline $\begin{array}{l}\text { normal weight (BMI 18.5-23.9 } \\
\left.\mathrm{kg} / \mathrm{m}^{2}\right), \mathrm{n}(\%)\end{array}$ & $737(45.0)$ & 291(51.9) & $446(41.4)$ & \\
\hline $\begin{array}{l}\left.\text { overweight (BMI } 24-27.9 \mathrm{~kg} / \mathrm{m}^{2}\right), \mathrm{n} \\
(\%)\end{array}$ & $469(28.6)$ & $153(27.3)$ & $316(29.4)$ & \\
\hline obese (BMI $\left.\geq 28 \mathrm{~kg} / \mathrm{m}^{2}\right), \mathrm{n}(\%)$ & $234(14.3)$ & $47(8.4)$ & $187(17.4)$ & \\
\hline neck circumference, cm & $38.4 \pm 38.5$ & $37.9 \pm 3.3$ & $38.6 \pm 3.6$ & 0.001 \\
\hline FVC, L & $2.70 \pm 0.94$ & $2.58 \pm 0.90$ & $2.77 \pm 0.96$ & $<0.001$ \\
\hline FEV1, L & $1.41 \pm 0.71$ & $1.29 \pm 0.63$ & $1.48 \pm 0.74$ & $<0.001$ \\
\hline FEV1\%pred & $54.0 \pm 22.5$ & $49.96 \pm 21.54$ & $\begin{array}{l}56.11 \pm \\
22.78\end{array}$ & $<0.001$ \\
\hline FEV1/FVC\% & $51.1 \pm 12.8$ & $49.3 \pm 12.5$ & $52.0 \pm 12.8$ & $<0.001$ \\
\hline GOLD stage, $(\mathrm{n}, \%)$ & & & & $<0.001$ \\
\hline GOLD 1 & $263(16.1)$ & $63(11.2)$ & $200(18.6)$ & \\
\hline GOLD 2 & $575(35.1)$ & 189(33.7) & $386(35.9)$ & \\
\hline GOLD 3 & $569(34.8)$ & $211(37.6)$ & $358(33.3)$ & \\
\hline GOLD 4 & $230(14.1)$ & $98(17.5)$ & $132(12.3)$ & \\
\hline AHI, events/h & $\begin{array}{l}13.35 \pm \\
15.09\end{array}$ & $2.09 \pm 1.46$ & $\begin{array}{l}19.21 \pm \\
15.65\end{array}$ & $<0.001$ \\
\hline TS90\% & $\begin{array}{l}12.74 \pm \\
22.98\end{array}$ & $8.00 \pm 19.61$ & $\begin{array}{l}15.20 \pm \\
24.20\end{array}$ & $<0.001$ \\
\hline Nadir SaO2, \% & $\begin{array}{l}80.73 \pm \\
10.97\end{array}$ & $84.72 \pm 8.46$ & $\begin{array}{l}78.65 \pm \\
11.54\end{array}$ & $<0.001$ \\
\hline Average SaO2, \% & $92.84 \pm 3.78$ & $93.61 \pm 3.45$ & $92.44 \pm 3.89$ & $<0.001$ \\
\hline \multicolumn{5}{|c|}{$\begin{array}{l}\text { Continuous variables were described as means } \pm \text { SD. Categorical variables were expressed as } \\
\text { percentages. P value for the difference between the groups. COPD, chronic obstructive pulmonary } \\
\text { disease. OVS, overlap syndrome. BMI, body mass index. GOLD, the global initiative for chronic } \\
\text { obstructive lung disease. mMRC dyspnea scale score, modified medical research council dyspnea } \\
\text { scale score. CAT score, COPD assessment test score. }\end{array}$} \\
\hline
\end{tabular}




\begin{tabular}{|c|c|c|c|c|}
\hline Parameter & $\begin{array}{l}\text { Total }(n= \\
\text { 1637) }\end{array}$ & $\begin{array}{l}\text { COPD only }(n= \\
561)\end{array}$ & $\begin{array}{l}\text { OVS( } n= \\
1076)\end{array}$ & $\begin{array}{l}\mathrm{P} \\
\text { Value }\end{array}$ \\
\hline mMRC dyspnea scale score & $1.7 \pm 1.0$ & $1.8 \pm 1.0$ & $1.7 \pm 1.0$ & 0.228 \\
\hline CAT score & $15.4 \pm 7.0$ & $15.7 \pm 7.4$ & $15.2 \pm 6.8$ & 0.945 \\
\hline Duration of COPD, months & $63.5 \pm 76.0$ & $64.8 \pm 75.7$ & $62.8 \pm 76.1$ & 0.693 \\
\hline $\begin{array}{l}\text { Acute exacerbation in previous year, } \\
\mathrm{n}(\%)\end{array}$ & $927(56.6)$ & $284(50.6)$ & $643(59.8)$ & $<0.001$ \\
\hline Hypertension, n(\%) & $657(40.1)$ & $200(35.7)$ & $457(42.5)$ & 0.008 \\
\hline Coronary artery disease, $\mathrm{n}(\%)$ & $255(15.6)$ & $84(15.0)$ & 171(15.9) & 0.627 \\
\hline Diabetes n (\%) & 187(11.4) & $62(11.1)$ & $125(11.6)$ & 0.733 \\
\hline Cerebrovascular disease, n (\%) & 167(10.2) & $67(11.9)$ & $100(9.3)$ & 0.093 \\
\hline \multicolumn{5}{|c|}{$\begin{array}{l}\text { Continuous variables were described as means } \pm \text { SD. Categorical variables were expressed as } \\
\text { percentages. P value for the difference between the groups. COPD, chronic obstructive pulmonary } \\
\text { disease. OVS, overlap syndrome. BMI, body mass index. GOLD, the global initiative for chronic } \\
\text { obstructive lung disease. mMRC dyspnea scale score, modified medical research council dyspnea } \\
\text { scale score. CAT score, COPD assessment test score. }\end{array}$} \\
\hline
\end{tabular}

\section{Association of BMI with OSA in COPD Patients}

Table 2 presents logistic regression of OSA with BMI or BMI category. There were three models: Crude, no adjustment; Model 1, adjusted for sex and age; Model 2, adjusted for sex, age, job, education degree, income, smoking status, alcohol consumption, FEV1\%pred, hypertension and acute exacerbation in previous year. BMI was classified into four categories: underweight $\left(B M l<18.5 \mathrm{~kg} / \mathrm{m}^{2}\right)$, normal weight (BMI:18.5-23.9 kg/m²), overweight (BMl: $24-27.9 \mathrm{~kg} / \mathrm{m}^{2}$ ) and obese (BMI $\geq 28 \mathrm{~kg} / \mathrm{m}^{2}$ ) according to Chinese criteria. 
Table 2

ORs $(95 \% \mathrm{Cl})$ of OSA according to BMIs in COPD

Crude

OR (95\% Cl) P value

$\mathrm{BMI}, \mathrm{Kg} / \mathrm{m}^{2}$

$\mathrm{BMI} \geq 24$ (overweight and

obese)
$1.055(1.029-1.081)$

$<0.001$

1.584(1.284-1.955)

$<0.001$
Model 1

OR (95\% Cl) P value

1.060(1.034-1.087)

$<0.001$

$1.644(01.329-2.035)$

$<0.001$
Model 2

OR $(95 \% \mathrm{Cl}) \mathrm{P}$ value

1.045(1.017-1.074)

0.001

1.465(1.166-1.840)

0.001

Classified BMI, Kg/m2

$\mathrm{BMI}<18.5$ (underweight)

$1.184(0.854-1.642)$

0.312

1.177(0.848-1.633)

0.331

$1.370(0.974-1.927)$

0.071

$18.5 \leq \mathrm{BMI}<24.0$ (normal
weight)

1.000 (Ref) -

1.000 (Ref) -

1.000 (Ref) -

weight)

$24.0 \leq \mathrm{BMI}<$

28.0(overweight)

$\mathrm{BMI} \geq 28$ (obese)

P for trend
$<0.001$

1.348(1.057-1.718)

0.016

$2.596(1.825-3.692)$

$<0.001$

$<0.00$

$<0.001$
1.264(0.980-1.630)

0.072 $<0.001$

BMI, body mass index. OR, odds ratio. Crude no adjustment; Model 1 adjusted for sex and age; Model 2 adjusted for sex, age, job, education, income, smoking, alcohol consumption, $\mathrm{FEV}_{1} \%$ pred, acute exacerbation in previous year, and high blood pressure.

BMI was significantly related to the risk of OSA in COPD patients, with a p value less than 0.001 in the crude model and model 1 . After fully adjusting for confounders in model 2 , the association remained significant. The estimated odds ratio (OR) per $1 \mathrm{~kg} / \mathrm{m}^{2}$ unit increase in BMI was 1.045 (95\% Cl 1.0171.074). When dividing patients into two categories according to $\mathrm{BMI}<24 \mathrm{~kg} / \mathrm{m}^{2}$ (normal and underweight) and $\mathrm{BMI} \geq 24 \mathrm{~kg} / \mathrm{m}^{2}$ (overweight and obese), the overweight and obese group had a $46.5 \%$ higher chance of OSA than the normal and underweight groups (OR 1.465, 95\% $\mathrm{Cl} 1.166-1.840$ ) in the fully adjusted models. Then, BMI was classified into four categories: underweight $\left(\mathrm{BMl}<18.5 \mathrm{~kg} / \mathrm{m}^{2}\right)$, normal weight (BMl:18.5-23.9 kg/m²), overweight (BMl: $24-27.9 \mathrm{~kg} / \mathrm{m}^{2}$ ) and obese $\left(\mathrm{BMI} \geq 28 \mathrm{~kg} / \mathrm{m}^{2}\right)$. BMI grade was significantly associated with OSA in the crude and adjusted models, with a $p$ value for trend $\leq 0.001$. Using BMI of $18.5-23.9 \mathrm{~kg} / \mathrm{m}^{2}$ (normal weight) as the reference group, the overweight group had a higher risk of OSA (OR 1.348, 95\% Cl 1.057-1.718) than the obese group (OR 2.596, 95\% Cl 1.825-3.692). After sex and age were adjusted, the association remained significant, and the risk increased slightly. In the fully adjusted model, the obese group still had a 2.623 -fold $(\mathrm{OR} 2.623,95 \% \mathrm{Cl}$ 1.805-3.811) higher risk of OSA than the normal weight group, but the overweight group had a trend 
toward a higher risk, with a p value of 0.072. Interestingly, the underweight group also showed a trend of a higher risk of OSA than the normal weight group, with a $p$ value of 0.071 .

\section{Restricted Cubic Spline Analyses in COPD Patients with OSA}

Figure 2 depicts a nonlinear relationship between BMI and the risk of OSA in this cohort of COPD patients.

We used the restricted cubic spline model with five knots to flexibly model and visualize the association of BMI with OSA in COPD patients (Fig. 2). The model was adjusted for confounders in model 2 (Table 2). The plot showed a $\mathrm{J}$ shaped relation between BMI and OSA. The risk for OSA was relatively flat at BMIs in the range of $20-24 \mathrm{~kg} / \mathrm{m}^{2}$ and then started to increase afterwards; unexpectedly, a BMI below 20 was associated with increased risk, although the magnitude varied ( $P$ for nonlinearity $0.0078, p$ for total < 0.0001).

\section{Discussion}

This was a prospective multicenter study from a national key research and development program about COPD. Data were exported from the electronic database of this program. A total of 1637 COPD patients with comorbid OSA were assessed. The prevalence of OSA in COPD patients was $65.7 \%$, with an OSA diagnosis indicated by $\mathrm{AHI} \geq 5$ events/h. A meta-analysis by Shawon and colleagues estimated that among COPD patients, OSA had a prevalence ranging from 2 to $65.9 \% .{ }^{9}$ These data suggested that OSA was prevalent in COPD patients. Although males accounted for more than $80 \%$ of the cohort, the OVS group had more male patients than the COPD-only group, showing that males were more likely to develop OSA even in the COPD cohort. In addition, retirees accounted for more than $45 \%$ of the patients, and the OVS group had more office clerks or workers and better income, which may correspond to more current smoking and alcohol consumption, higher BMI and larger neck circumference, which are established risk factors for OSA. ${ }^{6,15,18-22}$ Cigarette smoking was very prevalent in this cohort of COPD patients who had a duration of COPD of more than 5 years. There were fewer than $20 \%$ patients who never smoked, and the proportions of current smokers among COPD patients and COPD patients who also had OSA were $56.3 \%$ and $48.0 \%$, respectively. Considering the high prevalence of COPD or OVS and the related disability, disease and economic burden, smoking prevention and cessation are of importance. The two groups had no significant difference in age, mMRC dyspnea scale score, CAT score or duration of COPD, which may indicate that they had a similar clinical status when enrolled in this study. Age did not differ between the two groups, which may be related to the prevalence of OSA reaching stabilization in the elderly group. ${ }^{23}$ Spirometry and PSG were performed while the patients were relatively stable. Even so, the COPD-only cohort had poorer lung function and more severe sleep-disordered breathing and worse nocturnal desaturation, accompanied by more hypertension and more frequent acute exacerbation in the previous year. These characteristics were also in line with our preliminary analysis. ${ }^{24}$ This finding may confirm that OSA indeed contributed to poor outcomes of COPD, as reported. ${ }^{7}$ 
To the best of our knowledge, this is the first study to extensively examine the role of BMI in the risk of OSA in COPD patients and examine nonlinearity in detail by using flexible spline models. First, our study is a national multicenter, cross-sectional and prospective survey with 1637 COPD cases included in the final analysis. Second, our data not only indicated the relationship of BMI with the risk of OSA in COPD patients but also examined different BMI categories. Finally, for the first time, the nonlinear relationship of BMI with OSA in COPD subjects was flexibly modeled and visualized by using the restricted cubic spline.

Our study showed that BMI or BMI category was significantly related to the risk of OSA in COPD patients, with a $p$ value or $p$ for trend $\leq 0.001$. The risk of OSA was 1.596 times higher in the obese group than in the normal weight group in the crude model; after sex and age were adjusted (Model 1), the risk increased slightly. When confounders, i.e., sex, age, job, education, income, smoking, alcohol consumption, $\mathrm{FEV}_{1} \%$ pred, acute exacerbation in previous year, and high blood pressure were fully adjusted (Model 2), the risk was still 2.623 times higher. These data confirm that obesity is an important risk factor for OSA in COPD patients. For the overweight group, compared with the normal weight group, the higher risk became no longer significant when confounders were fully adjusted, but there remained a trend of higher risk with a $p$ value of 0.072 . This may relate to reverse causality and the control of covariates, such as smoking or spirometry. Unexpectedly, the underweight group also showed a trend of a higher risk of OSA than the normal weight group, with a $p$ value of 0.071 . We further investigated the relationship of BMI with OSA in this cohort of COPD patients using a restricted cubic model. The plot showed that BMI had a J-shaped association with OSA in COPD patients, with the lowest risk in the range of $20-24 \mathrm{~kg} / \mathrm{m}^{2}$. Studies have reported that BMI has a J-shaped, U-shaped or inverse association for adverse outcomes of respiratory disease. ${ }^{13,25,26}$ A population-based cohort study of 3.6 million UK adults showed that BMI had a J-shaped association with respiratory diseases, with the nadir of risk occurring in the range of $21-25 \mathrm{~kg} / \mathrm{m}^{2} .{ }^{25}$ Therefore, it makes sense that a healthy weight plays a vital role in the prognosis of chronic disease. Follow-up studies and meta-analyses indicated that among COPD patients, low BMI was associated with higher mortality. ${ }^{27-29} \mathrm{~A}$ National Survey from Korea showed that low BMI contributed to COPD development and mortality, while normal or higher than normal weight had a protective effect. ${ }^{30}$ However, a large, randomly selected population study by Landbo et al. ${ }^{31}$ suggested that obesity had a protective effect in severe COPD patients, but in those with mild to moderate disease, obesity was associated with a worse prognosis. Moreover, a follow-up study of 968 COPD patients enrolled from the hospital reported that after adjusting for confounders, including GOLD stage, the optimal BMI with the lowest risk for death was in the overweight category: $25.09-26.56 \mathrm{~kg} / \mathrm{m}^{2} .{ }^{32} \mathrm{~A}$ study in the general population suggested that BMI $\varangle 24.4 \mathrm{~kg} / \mathrm{m}^{2}$ was a risk factor for COPD in OSA patients, and being overweight but not obese likely protects moderate to severe OSA patients from the risk of COPD. ${ }^{33}$ Therefore, it is possible that a healthy weight or overweight may protect against the development of OSA in patients with COPD. This hypothesis, which is mainly speculative, needs further study. To our knowledge, no survey has evaluated classified BMI with the risk of OSA in a COPD cohort.

Notably, OSA is highly prevalent in obese individuals and has been investigated extensively. $4,18,34$ Although few studies have investigated the prevalence of OSA in underweight people, a Japanese study 
of 3659 OSA patients from 11 hospitals showed that underweight patients exhibited a higher AHI than normal weight patients. ${ }^{35} \mathrm{~A}$ recent survey showed that lower BMI was a risk factor for OSA in elderly Thai hypertensive patients. ${ }^{36}$ In this study, we hypothesize that several factors might explain the association of OSA with COPD patients with low BMI. First, COPD patients with low BMI may have poor nutritional status and more body wasting, which results in reductions in ventilation and activities of upper airway muscle function and increases upper airway resistance. ${ }^{37-39}$ Second, the position during sleep also impacts the upper airway. A study of diagnosed OSA patients who underwent drug-induced sleep endoscopy showed that the prevalence of tongue-base obstruction in patients with low BMI was $100 \%$ in the supine position. ${ }^{40}$. Third, narrowing of the upper airway can occur due to inflammation. Cigarette smoking-induced upper airway inflammation likely contributes to OSA. Stokes et al. showed that overweight/obese individuals are less likely to smoke than their normal weight counterparts. ${ }^{41}$ Similar behavior may be present in COPD patients with a low BMI. OSA also appears to exacerbate lower airway inflammation. ${ }^{42}$ In addition, inhaled corticosteroids may contribute to OSA by causing upper airway myopathy or extrapulmonary inflammation, which may impair upper airway reflexes or neuromuscular responses. ${ }^{43-45}$ Finally, the extent of emphysema and chronic bronchitis influence the occurrence of OSA. Studies show that lung hyperinflation against the risk of OSA by lowering the critical closing pressure of the upper airway, while chronic bronchitis predisposes patients to a higher risk of OSA due to lower respiratory drive and peripheral fluid retention in the cor pulmonale. ${ }^{46-48}$ In fact, a majority of COPD patients have a mixture of emphysema and chronic bronchitis, and the risk of OSA is associated with protective and promoting factors in COPD patients.

Therefore, it may be reasonable that BMI had a J-shaped association with OSA, with the lowest risk in the range of $20-24 \mathrm{~kg} / \mathrm{m}^{2}$ and lower or higher than normal weight associated with a higher risk of OSA in COPD patients. Unintentional weight loss should perhaps be considered a deleterious factor rather than obesity as a protective one. Maintaining a healthy weight should be recommended. In the present study, the low BMI group showed a trend toward a higher risk of OSA than the normal weight group, but the difference was not significant. In the future, prospective and follow-up studies focusing on the relation of low BMI and BMI category with OSA and prognosis in COPD patients are needed to shed light on this complex issue.

There are some limitations in this study. This was a multicenter, cross-sectional study, the data may be heterogenous and potential recall bias cannot be excluded. In addition, patients were enrolled from inpatient or outpatient clinics, and although lung function tests and PSG were performed under the guidance of professional technicians when subjects were in a stable state, the patients may be somewhat different from the general population. However, the project leaders, main researchers and specialists in related fields engaged in discussion and agreed on these issues before the study was conducted. The unified criterion, standardized instruments, standardized operations, standardized projects and processes and relatively large sample could minimize bias and heterogeneity.

\section{Conclusions}


OSA is a frequent finding in COPD patients and may be an important contributor to poor outcomes. BMI is significantly associated with risk of OSA. The restricted cubic spline model showed a J-shaped relation between $\mathrm{BMI}$ and OSA. The risk for OSA was relatively flat at BMls in the range of $20-24 \mathrm{~kg} / \mathrm{m}^{2}$ and then started to increase afterwards; unexpectedly, for BMls below 20, the risk also increased, although the magnitude varied.

\section{List Of Abbreviations}

COPD, chronic obstructive pulmonary disease; OSA, obstructive sleep apnea; OVS, overlap syndrome; BMI, body mass index; PSG, polysomnography; GOLD, the global initiative for chronic obstructive lung disease; mMRC dyspnea scale score, modified medical research council dyspnea scale score; CAT score, COPD assessment test score; OR, odds ratio.

\section{Declarations}

\section{Ethics approval and consent to participate:}

The protocol of this study was reviewed and approved by the Ethics Committee of Renmin Hospital of Wuhan University (No.2017K-C014). The trial was conducted in compliance with the Declaration of Helsinki and every patient included in this study was informed about the purpose of the study and written consent was signed.

\section{Consent for publication:}

Agreed.

\section{Availability of data and materials:}

This project is still going on and our present study is one part of this project. Thus, these data cannot available till the program is fully completed, but if requested data will be made available.

\section{Competing interests:}

The authors declared no conflicts of interest for this work

\section{Funding:}

This work was supported by grants from the National Natural Science Foundation of China (No. 81970082) and the National Key Research and Development Program of China (No. 2016YFC1304403).

\section{Acknowledgements:}

We thanked the funding and our colleagues who contributed to this study. Thanks for English native speaker in American Journal Experts for professional language editing of the manuscript Authors' 
contributions.

\section{References}

1. Malhotra A, Schwartz AR, Schneider H, et al. Research Priorities in Pathophysiology for Sleepdisordered Breathing in Patients with Chronic Obstructive Pulmonary Disease. An Official American Thoracic Society Research Statement. American journal of respiratory and critical care medicine 2018;197:289-99.

2. Vogelmeier CF, Criner GJ, Martinez FJ, et al. Global Strategy for the Diagnosis, Management, and Prevention of Chronic Obstructive Lung Disease 2017 Report. GOLD Executive Summary. American journal of respiratory and critical care medicine 2017;195:557-82.

3. Wang C, Xu J, Yang L, et al. Prevalence and risk factors of chronic obstructive pulmonary disease in China (the China Pulmonary Health [CPH] study): a national cross-sectional study. Lancet (London, England) 2018;391:1706-17.

4. Lim DC, Pack Al. Obstructive Sleep Apnea: Update and Future. Annual review of medicine 2017;68:99-112.

5. Povitz M, Bolo CE, Heitman SJ, Tsai WH, Wang J, James MT. Effect of treatment of obstructive sleep apnea on depressive symptoms: systematic review and meta-analysis. PLoS medicine 2014;11:e1001762.

6. Young T, Peppard PE, Gottlieb DJ. Epidemiology of obstructive sleep apnea: a population health perspective. American journal of respiratory and critical care medicine 2002;165:1217-39.

7. McNicholas WT. COPD-OSA Overlap Syndrome: Evolving Evidence Regarding Epidemiology, Clinical Consequences, and Management. Chest 2017;152:1318-26.

8. Marin JM, Soriano JB, Carrizo SJ, Boldova A, Celli BR. Outcomes in patients with chronic obstructive pulmonary disease and obstructive sleep apnea: the overlap syndrome. American journal of respiratory and critical care medicine 2010;182:325-31.

9. Shawon MS, Perret JL, Senaratna CV, Lodge C, Hamilton GS, Dharmage SC. Current evidence on prevalence and clinical outcomes of co-morbid obstructive sleep apnea and chronic obstructive pulmonary disease: A systematic review. Sleep medicine reviews 2017;32:58-68.

10. Naranjo M, Willes L, Prillaman BA, Quan SF, Sharma S. Undiagnosed OSA May Significantly Affect Outcomes in Adults Admitted for COPD in an Inner-City Hospital. Chest 2020;158:1198-207.

11. Adams KF, Schatzkin A, Harris TB, et al. Overweight, obesity, and mortality in a large prospective cohort of persons 50 to 71 years old. The New England journal of medicine 2006;355:763-78.

12. Chen Z, Yang G, Offer A, et al. Body mass index and mortality in China: a 15-year prospective study of 220000 men. International journal of epidemiology 2012;41:472-81.

13. Lee DH, Keum N, Hu FB, et al. Predicted lean body mass, fat mass, and all cause and cause specific mortality in men: prospective US cohort study. BMJ (Clinical research ed) 2018;362:k2575. 
14. Sun $\mathrm{Y}$, Milne $\mathrm{S}$, Jaw JE, et al. BMI is associated with FEV(1) decline in chronic obstructive pulmonary disease: a meta-analysis of clinical trials. Respiratory research 2019;20:236.

15. Wall H, Smith C, Hubbard R. Body mass index and obstructive sleep apnoea in the UK: a crosssectional study of the over-50s. Primary care respiratory journal : journal of the General Practice Airways Group 2012;21:371-6.

16. Berry RB, Budhiraja R, Gottlieb DJ, et al. Rules for scoring respiratory events in sleep: update of the 2007 AASM Manual for the Scoring of Sleep and Associated Events. Deliberations of the Sleep Apnea Definitions Task Force of the American Academy of Sleep Medicine. Journal of clinical sleep medicine : JCSM : official publication of the American Academy of Sleep Medicine 2012;8:597-619.

17. Zhou BF. Predictive values of body mass index and waist circumference for risk factors of certain related diseases in Chinese adults--study on optimal cut-off points of body mass index and waist circumference in Chinese adults. Biomedical and environmental sciences : BES 2002;15:83-96.

18. Senaratna CV, Perret JL, Lodge CJ, et al. Prevalence of obstructive sleep apnea in the general population: A systematic review. Sleep medicine reviews 2017;34:70-81.

19. Black JK, Whittaker AC, Balanos GM. Undiagnosed Obstructive Sleep Apnea and Physical Activity in Older Manual Workers. Journal of aging and physical activity 2019;27:293-9.

20. Chung F, Subramanyam R, Liao P, Sasaki E, Shapiro C, Sun Y. High STOP-Bang score indicates a high probability of obstructive sleep apnoea. British journal of anaesthesia 2012;108:768-75.

21. Patel SR. Obstructive Sleep Apnea. Annals of internal medicine 2019;171:Itc81-itc96.

22. Johnson DA, Guo N, Rueschman M, Wang R, Wilson JG, Redline S. Prevalence and correlates of obstructive sleep apnea among African Americans: the Jackson Heart Sleep Study. Sleep 2018;41.

23. Sanders MH, Newman AB, Haggerty CL, et al. Sleep and sleep-disordered breathing in adults with predominantly mild obstructive airway disease. American journal of respiratory and critical care medicine 2003;167:7-14.

24. Xiong MQ, Hu WH, Hu K, et al. [Analysis of risk factors and consequences for concurrent obstructive sleep apnea in chronic obstructive pulmonary disease patients]. Zhonghua jie he he hu xi za zhi = Zhonghua jiehe he huxi zazhi $=$ Chinese journal of tuberculosis and respiratory diseases 2019;42:832-7.

25. Bhaskaran K, Dos-Santos-Silva I, Leon DA, Douglas IJ, Smeeth L. Association of BMI with overall and cause-specific mortality: a population-based cohort study of 3.6 million adults in the UK. The lancet Diabetes \& endocrinology 2018;6:944-53.

26. Yang $L$, Zhou M, Smith M, et al. Body mass index and chronic obstructive pulmonary disease-related mortality: a nationally representative prospective study of 220,000 men in China. International journal of epidemiology 2010;39:1027-36.

27. Schols AM, Slangen J, Volovics L, Wouters EF. Weight loss is a reversible factor in the prognosis of chronic obstructive pulmonary disease. American journal of respiratory and critical care medicine 1998;157:1791-7. 
28. Celli BR, Cote CG, Marin JM, et al. The body-mass index, airflow obstruction, dyspnea, and exercise capacity index in chronic obstructive pulmonary disease. The New England journal of medicine 2004;350:1005-12.

29. Yamauchi Y, Hasegawa W, Yasunaga H, et al. Paradoxical association between body mass index and in-hospital mortality in elderly patients with chronic obstructive pulmonary disease in Japan. International journal of chronic obstructive pulmonary disease 2014;9:1337-46.

30. Park HJ, Cho JH, Kim HJ, Park JY, Lee HS, Byun MK. The effect of low body mass index on the development of chronic obstructive pulmonary disease and mortality. Journal of internal medicine 2019;286:573-82.

31. Landbo C, Prescott E, Lange P, Vestbo J, Almdal TP. Prognostic value of nutritional status in chronic obstructive pulmonary disease. American journal of respiratory and critical care medicine 1999;160:1856-61.

32. Lainscak M, von Haehling S, Doehner W, et al. Body mass index and prognosis in patients hospitalized with acute exacerbation of chronic obstructive pulmonary disease. Journal of cachexia, sarcopenia and muscle 2011;2:81-6.

33. Choi KM, Thomas RJ, Kim J, Lee SK, Yoon DW, Shin C. Overlap syndrome of COPD and OSA in Koreans. Medicine 2017;96:e7241.

34. Young T, Peppard PE, Taheri S. Excess weight and sleep-disordered breathing. Journal of applied physiology (Bethesda, Md : 1985) 2005;99:1592-9.

35. Ohdaira F, Nakamura K, Nakayama H, et al. Demographic characteristics of 3,659 Japanese patients with obstructive sleep apnea-hypopnea syndrome diagnosed by full polysomnography: associations with apnea-hypopnea index. Sleep \& breathing = Schlaf \& Atmung 2007;11:93-101.

36. Sawanyawisuth $\mathrm{K}$, Chindaprasirt J, Senthong V, et al. Lower BMI is a predictor of obstructive sleep apnea in elderly Thai hypertensive patients. Sleep \& breathing = Schlaf \& Atmung 2013;17:1215-9.

37. Schols AM, Broekhuizen R, Weling-Scheepers CA, Wouters EF. Body composition and mortality in chronic obstructive pulmonary disease. The American journal of clinical nutrition 2005;82:53-9.

38. Lenk K, Schuler G, Adams V. Skeletal muscle wasting in cachexia and sarcopenia: molecular pathophysiology and impact of exercise training. Journal of cachexia, sarcopenia and muscle 2010;1:9-21.

39. Worsnop C, Kay A, Kim Y, Trinder J, Pierce R. Effect of age on sleep onset-related changes in respiratory pump and upper airway muscle function. Journal of applied physiology (Bethesda, Md : 1985) 2000;88:1831-9.

40. Woo HJ, Lim JH, Ahn JC, et al. Characteristics of Obstructive Sleep Apnea Patients With a Low Body Mass Index: Emphasis on the Obstruction Site Determined by Drug-Induced Sleep Endoscopy. Clinical and experimental otorhinolaryngology 2020;13:415-21.

41. Stokes A, Preston SH. Smoking and reverse causation create an obesity paradox in cardiovascular disease. Obesity (Silver Spring, Md) 2015;23:2485-90. 
42. Wang Y, Hu K, Liu K, et al. Obstructive sleep apnea exacerbates airway inflammation in patients with chronic obstructive pulmonary disease. Sleep medicine 2015;16:1123-30.

43. Teodorescu M, Consens FB, Bria WF, et al. Predictors of habitual snoring and obstructive sleep apnea risk in patients with asthma. Chest 2009;135:1125-32.

44. Teodorescu M, Xie A, Sorkness CA, et al. Effects of inhaled fluticasone on upper airway during sleep and wakefulness in asthma: a pilot study. Journal of clinical sleep medicine : JCSM : official publication of the American Academy of Sleep Medicine 2014;10:183-93.

45. Kimoff RJ. Upperairway myopathy is important in the pathophysiology of obstructive sleep apnea. Journal of clinical sleep medicine : JCSM : official publication of the American Academy of Sleep Medicine 2007;3:567-9.

46. Biselli P, Grossman PR, Kirkness JP, et al. The effect of increased lung volume in chronic obstructive pulmonary disease on upper airway obstruction during sleep. Journal of applied physiology (Bethesda, Md : 1985) 2015;119:266-71.

47. Krachman SL, Tiwari R, Vega ME, et al. Effect of Emphysema Severity on the Apnea-Hypopnea Index in Smokers with Obstructive Sleep Apnea. Annals of the American Thoracic Society 2016;13:112935.

48. White LH, Bradley TD. Role of nocturnal rostral fluid shift in the pathogenesis of obstructive and central sleep apnoea. The Journal of physiology 2013;591:1179-93.

\section{Figures}




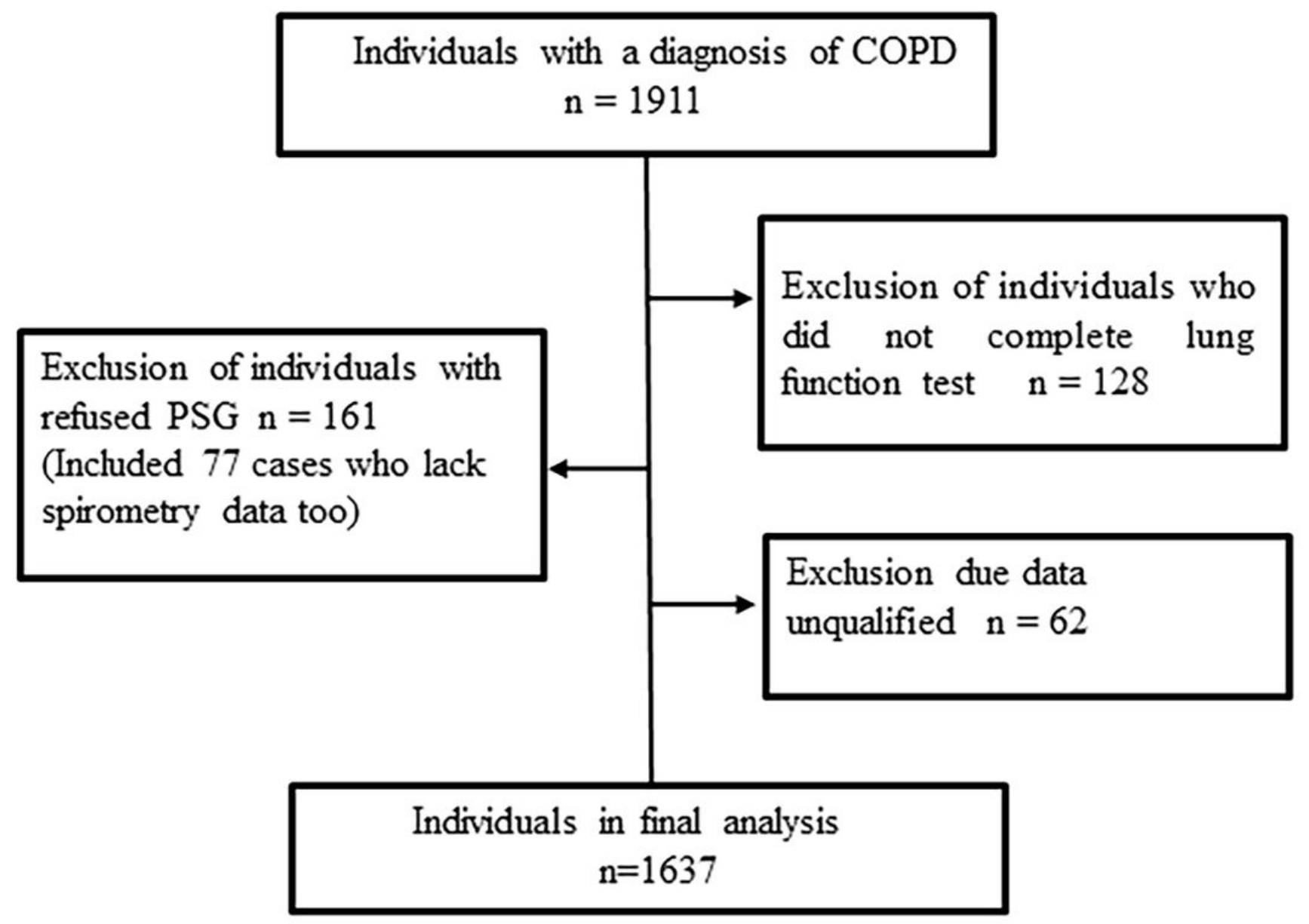

Figure 1

Flow of participants through the study. COPD, chronic obstructive pulmonary disease. PSG, polysomnography. 


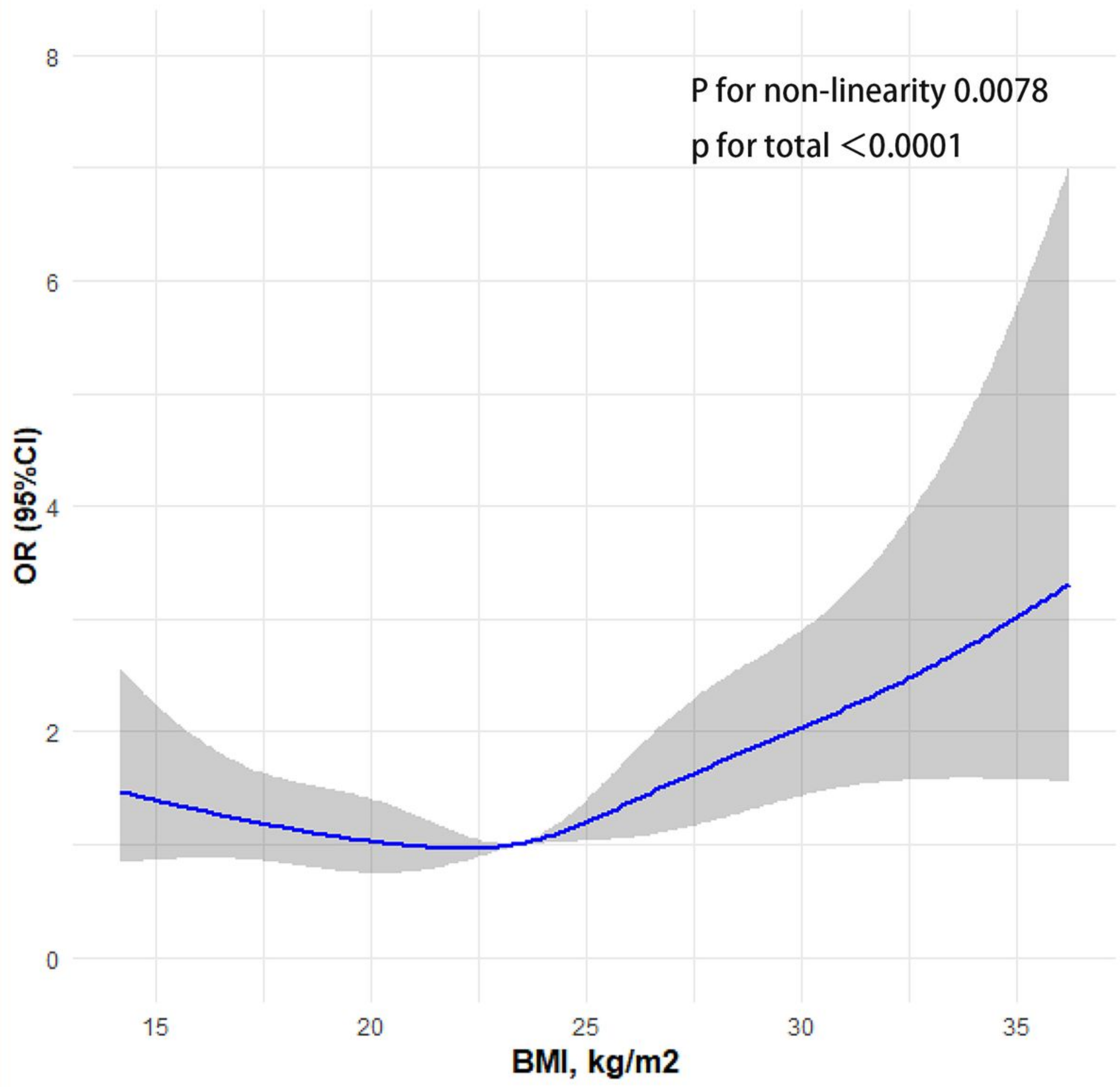

Figure 2

Association between BMI and risk of OSA in COPD patients. Estimates adjusted for sex, age, job, education, income, smoking, alcohol consumption, FEV1\%pred, acute exacerbation in previous year, and high blood pressure. The dashed area represents the $95 \% \mathrm{Cl}$. BMI, body mass index. OR, odds ratio. 